\title{
15 \\ Academic In/Civility: Co-Constructing the Foundation for a Civil Learning Community
}

\author{
Zopito Marini \\ Brock University \\ Christine Polihronis \\ Carleton University \\ Wendy Blackwell \\ Brock University
}

While it has important implications for the success of students as well as for institutions, academic in/civility is not an issue that is readily engaged by many professors. However, the creation of a civil learning community should be a high priority for everyone in the academe for it has the potential to benefit both individuals and institutions. The exercises outlined in this paper should help professors to engage students in reflective activities designed to provide valuable information about individual understanding and perceptions of in/civility as well as to provide opportunities for developing a shared vision and foundation for a civil learning community.

\section{Introduction}

\begin{abstract}
lthough it is a growing concern for students Aand professors, academic in/civility remains difficult to define and to categorize. Consequently, developing prevention strategies is a challenge. Our conceptualization of civility consists of two dimensions: the "civic" aspect, in which the focus is on "citizenship" (i.e., consideration of the well-being of the entire class), and the "civil" as-
\end{abstract}

pect, in which the focus is on mechanisms used to secure the well-being of the class by cultivating "learning relationships" (i.e., respect for the "other" students and for the learning process). Given these conditions, in a civil learning community, students are more likely to focus on their learning and self-development as well as to actively participate and contribute to the life of their 
classrooms. A civil environment allows professors to focus on their teaching and reduce misunderstandings, conflicts, and confrontations, which can seriously damage the professor-student learning relationship.

The purpose of this paper is to outline our experience of developing a framework designed to foster an understanding of incivility with the view of designing teaching environments that promote civility and nurture the fragile teaching and learning process. This paper has three specific aims, namely: 1) to broaden our understanding of the nature of in/ civility; 2) to provide a framework within which to categorize examples of uncivil behaviours; and 3) to make suggestions for fostering civility in the classroom by co-constructing a declaration of civility as a foundation for a civil learning community.

\section{Precursors to a Design for Civility: Understanding Incivility and its Antisocial Bullying Foundation}

Two initiatives have informed our understanding of incivility. The first has focused on broadening our appreciation of the range of uncivil acts. For instance, we have encouraged students to expand their conception of incivility to include behaviours as well as attitudes. Furthermore, we have favoured a much more comprehensive approach that includes a range of acts from talking in class, cheating on exams, misusing technology, overreacting to perceived provocation, and so on. We have also found it informative to conceptualize the gravity of uncivil behaviours along a continuum, ranging from minor occurrences, such as disrupting lectures by means of loud conversations, to the more serious ones like when insults, threats, or other forms of intimidation are used and safety becomes an issue. In our efforts to help students construct a more comprehensive metric regarding the continuum of incivility, we also deemed it important to consider the severity of the outcome of various acts. In terms of consequences, the experience of incivility can affect a student's academic and personal development in different ways, ranging from short- term disengagement in a course to long-term unfulfilled educational goals (Hirschy \& Braxton, 2004).

The second initiative we have undertaken has focused on attempts to categorize occurrences of academic incivility in a systematic manner by examining them through the lens of our research on bullying (Marini \& Dane, 2008; Marini, Dane, Bosacki, \& YLC-CURA, 2006; Marini, Dane, \& Kennedy, 2010). Adopting the Multidimensional Bullying Identification Model (see Marini, 2009) has permitted us to consider the finer-grained dimensions of incivility, and we have been able to define and categorize many of the uncivil acts reported by our students. Thus, when we ask our students about their experience of incivility, we can arrange their responses in terms of the form (i.e., type), function (i.e., motivation), type of involvement (i.e., from passive to active to aggressive), and in terms of the severity of outcome (i.e., from low or annoying, to mid or disruptive, to high or dangerous). For instance, in terms of form, the distinction between direct and indirect acts of incivility hinges on whether an uncivil act is carried out overtly, that is in plain view, or covertly, where attempts are made to conceal the act. With respect to motivation, it is helpful to differentiate between behaviours that arise due to a frustrating reaction to a perceived provocation (i.e., lashing out against a peer who does not agree with your point of view), from the proactive one, such as those that are planned and intentional (i.e., spreading rumours about a student in a seminar). In regard to types of involvement, these can range from passive to active to aggressive. Thus, in terms of intervention, it is helpful to distinguish those students who are passively involved (e.g., reading a newspaper in class) from those who are actively involved (e.g., talking during lectures), and those who are aggressive (e.g., publicly and loudly questioning the instructor's competence or the fairness of the grade received on an assignment). In regard to the severity of outcomes, here, again we underscore the importance of locating the impact of incivility along a continuum, ranging from annoying to disruptive to dangerous.

Figure 1 provides a template for this initiative, which involves engaging students in a structured discussion of incivility. Therefore, after collecting 


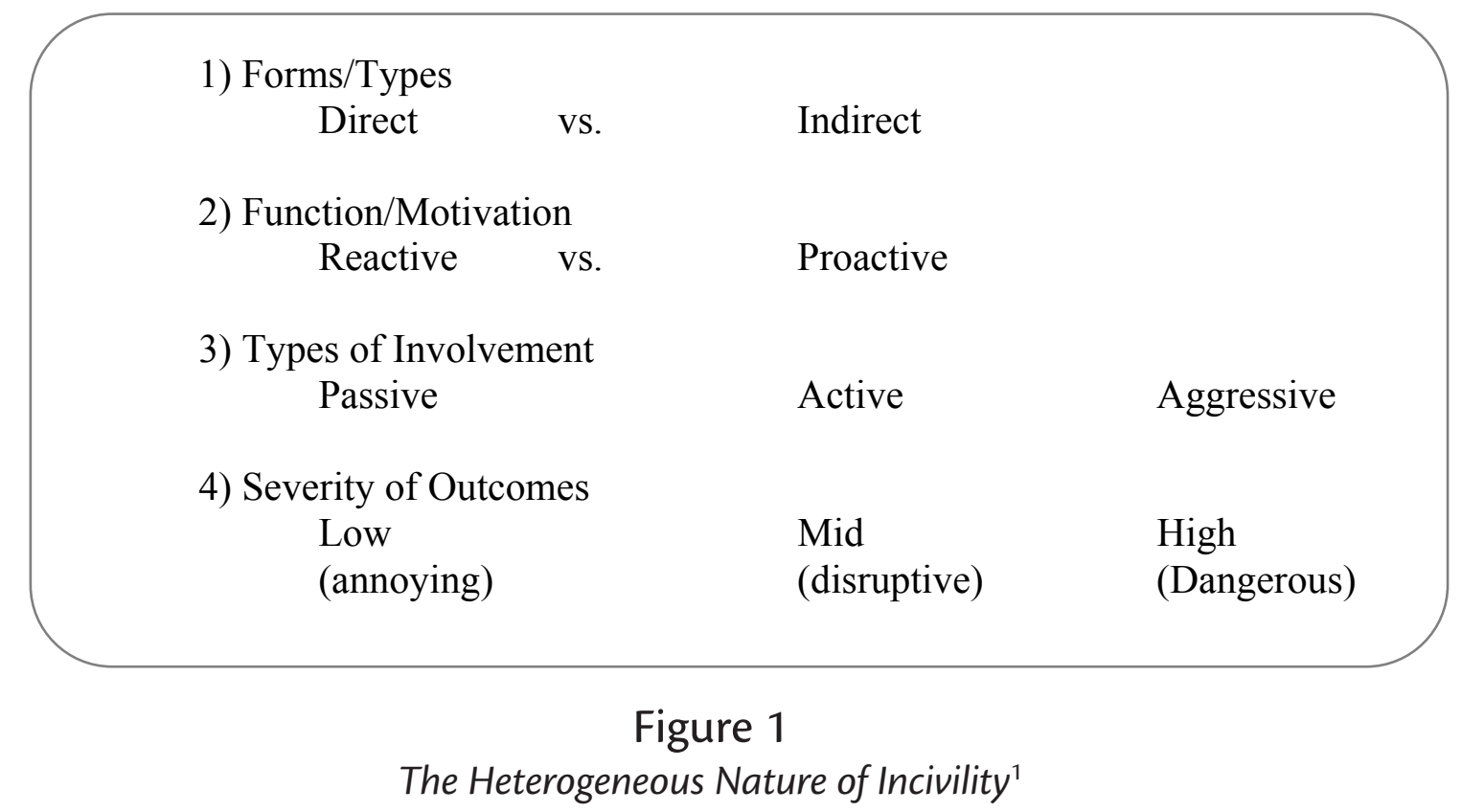

students' accounts of incivility, their responses are separated into four categories to determine the type of lived experiences they bring to class, namely: 1) Forms; 2) Function; 3) Types of Involvement; and 4) Severity of Outcomes.

\section{Design for a Civil Learning Community: Co-Constructing a Declaration of Civility}

The distinctions made above help to pave the way towards general intervention strategies. For instance, while direct and reactive incivilities can usually be addressed by instructional interventions, which may include explicit statements on a syllabus about classroom "civic" expectations, other acts of incivility need to be addressed by different means, which include the fostering of positive learning relationships between students and between students and their instructors (Marini, 2007, 2009). In other words, to effectively address "civil" concerns that are connected to indirect and intentional incivilities and to minimize their subtle and hard-to-notice impact, it may be more effective if we attempt to build a shared understanding of what civility means to our students, and to create a statement outlining how we will relate to each other in our learning environment, and how we will resolve conflicts when they invariably arise. Thus, the following series of exercises is aimed at creating "civil" and healthy relationships, which are the foundation for a civil learning community.

\section{Step 1: Defining Civility}

The aim of this segment is to explore students' understanding of the term "civility." All of these activities work best when engagement is allowed to take place first at the individual level and then at the group level. It is important that individual voices be heard and given plenty of space. We begin the process by asking students to define civility by writing (or drawing) what it means to each of them. Once the individual contributions are completed, the group can be guided through an exercise of identifying some of the themes noted in the individual contributions. The purpose of this segment is to highlight key words and themes that represent the best definition of civility that the group has produced. Here are some possible examples of ci-

\footnotetext{
${ }^{1}$ Adapted from Marini, 2009; Marini, Dane, \& Kennedy, 2010.
} 
vility: mutual respect; perspective-taking; not cheating on exams; using technology properly; acceptance of diversity; caring, and feeling connected.

\section{Step 2: Operationalizing Civility}

In this segment, students are invited to describe in writing how they are going to make the definition of civility concrete. This important step will allow students some time to reflect on what they consider to be a manifestation of civility. At the group level, it is critical that a robust discussion take place in which different views are exchanged and assumptions are tested regarding the range of possible behaviours involved in civility. For example, what does mutual respect look like in a seminar? Similarly, what does considerate mean (e.g., students may be encouraged to think about the environment created by a considerate individuals)? Depending on the time available, it is worth engaging students in brief role-playing exercises. For instance, what would the group do if a student were to chew gum loudly while the people around him/her are trying to focus on the seminar? More seriously, how would they make the theme of being respectful concrete in the context of a seminar discussion on the acceptance of diversity in a heterogeneous group? In this case, students may want to engage in some form of self-regulation where they would refrain from voicing their "uninformed" opinion on diversity by reflecting on the fact that it may hurt a classmate. The desired outcomes of this segment are those of building on the definitions from Step 1 and of giving life to what civility means for the group, in concrete behavioural terms as well as attitude. In other words, we want to provide opportunities for individuals and the group to reflect and express their opinions on how they will "live" their civility.

\section{Step 3: Constructing a Declaration of Civility}

In this segment, individuals are asked to generate a "statement of civility" that they believe the entire group may adopt. If students experience difficulties during this step, the instructor may have to remind them that the components of this statement should flow from the previous two steps. At the group level, the entire class is guided to generate "a communal declaration of civility."

\section{Step 4: Sustaining Civility}

It is important to make provisions for civility to continue beyond the first few weeks of a term. Therefore, it is valuable for students to engage in the development of their own classroom's declaration of civility. It is also important for an instructor to be vigilant of the process and, in some cases, to intervene with tactful suggestions aimed at putting in place mechanisms which ensure that civility is sustained through peaceful times as well as times of conflict. To that end, the instructor has to see to it that at least three key components are present in any communal declaration, including: 1) a definition of civility that acknowledges the importance of the learning relationship and makes mention of the concern for both the individual and the group; 2) a clear outline of the expectations of behaviour in peaceful times as well as in times of conflict (i.e., provide concrete examples of what we expect our civility to look like in good times [e.g., when we are in agreement on an issue] and in difficult times [e.g., when we are not in agreement]); and 3) an outline of the social mechanisms that will allow reparation of the learning relationship when it becomes strained, such as offering an apology when a line is crossed and someone is hurt, or offering to meet for the purpose of voicing concerns in the presence of a third party. The instructor may want to end this segment by inviting students to reflect on how they may be able to promote civility inside and outside the classroom.

As a final note, it is advantageous to carry out these activities as a group at the beginning of the academic term (usually the second week of class is best, rather than the first week when administrative details are the primary focus). This will set a positive tone and strengthen the social and human component of a learning relationship, thus facilitating the in vivo building of a shared understanding of civility. However, if this is not possible because of time pressure, an alternative to consider is that of engaging students electronically using the discussion boards available on most course management programs.

Taking students through these activities allows them to reflect on the importance of understanding the many dimensions of in/civility and offers them the opportunity to take ownership and re- 
sponsibility for co-constructing a healthy, functional, and civil learning community for themselves and for those around them.

\section{References}

Hirschy, A.S. \& Braxton, J.M. (2004). Effects of student classroom incivilities on students. New Directions in Teaching and Learning, 99, 67-76.

Marini, Z.A. (2007). Understanding and fostering civility in university classrooms: Seminar leaders as agents of civic engagement. Research proposal: Brock Chancellor's Chairs for Teaching Excellence. Unpublished manuscript, Brock University.

Marini, Z.A. (2009). The thin line between civility and incivility: Fostering reflection and selfawareness to create a civil learning community. In A. Wright, M. Wilson, \& D. MacIsaac (Eds.), Collected Essays on Learning and Teaching, 2, 61-67.

Marini, Z.A. \& Dane, A.V. (2008). Matching interventions to bullying subtypes: Ensuring programs fit the multifaceted needs of children involved in bullying. In D. Pepler \& W. Craig (Eds.), An international perspective on understanding and addressing bullying (pp. 97-126). Bloomington, IN: AuthorHouse.

Marini, Z.A, Dane, A., Bosacki, S., \& YLC-CURA. (2006). Direct and indirect bully-victims: Differential psychosocial risk factors associated with adolescents involved in bullying and victimization. Aggressive Behavior, 32, 551-569.

Marini, Z.A., Dane, A., \& Kennedy, R. (2010). Multiple pathways to bullying: Tailoring educational practices to variations in students' temperament and brain function. In M. Ferrari \& L. Vuletic (Eds.), Developmental in- terplay of mind, brain, and education: Essays in honor of Robbie Case (pp. 257-291). New York: Springer.

\section{Authors' Note}

The present paper builds on the material presented in Marini (2009) and is based, in part, on the reflections generated by the presentation made at the 2009 STLHE Conference at the University of New Brunswick. This work is supported by a Brock Chancellor's Chair for Teaching Excellence.

\section{Biographies}

Zopito Marini is a Professor of Child and Youth Studies at Brock University. His commitment to the development of innovative pedagogy has been acknowledged with many awards, including the OCUFA (Ontario Confederation of Faculty Associations) Teaching Award, and a 3M National Teaching Fellow. He has received a Brock Chancellor's Chair for Teaching Excellence to continue his investigation on the causes and consequences of in/civility in the classroom.

Christine Polihronis is a first year M.A. student in the Department of Psychology at Carleton University. As a part of the Healthy Relationships Lab, her research interests include the social and cognitive development of children and adolescents involved in aggression. More specifically, she is interested in how moral disengagement contributes to an uncivil learning community.

Wendy Blackwell is married with three sons. She spent many hours volunteering in public schools. Eventually her passion for working with children led her to Brock University where she is currently completing her Bachelor of Arts and Bachelor of Education degrees concurrently. She is interested in pursuing a graduate degree to investigate the applications of civility in elementary school environment. 